\title{
HIV
}

\section{HIV-1 seronegativity in a child with proved perinatal HIV infection on HAART}

\author{
N Desai, M Mathur, K Abu-Lawi
}

Sex Transm Infect 2005;81:377-379. doi: 10.1136/sti.2004.011973

Objectives: To report the unexpected absence of HIV-1 antibodies and provirus in the peripheral blood of a 4 year old with previously diagnosed perinatal HIV infection.

Methods: Case study including review of clinic and laboratory records and confirmation of results of HIV-1 enzyme linked immunosorbent assay (ELISA), western blot, and HIV-1 DNA PCR from reference laboratory.

Results: This child had high plasma viral load at the initiation of highly active antiretroviral therapy (HAART) at 10 months of age. Following undetectable HIV viraemia continuously for a 3 year period, he had normal CD4 and immunoglobulin levels. When retested at the request of the parent, HIV-1 ELISA, western blot, and HIV DNA PCR were all negative, raising the question of misdiagnosis and the parental misperception of a "cure." A rebound increase in viral load on cessation of therapy led to these diagnostic tests becoming positive again, with better parental acceptance of the diagnosis and treatment plan.

Conclusions: Patients and providers should exercise caution in interpreting negative serological tests in children on HAART.

$\mathrm{H}$ IV infection is diagnosed in children older than 18 months and in adults by detection of antibodies to HIV by enzyme linked immunosorbent assay (ELISA). A baby born to a HIV infected mother manifests a positive ELISA at birth because of transplacental transfer of maternal IgG antibodies to HIV that may persist for months. This signifies perinatal exposure to HIV but does not necessarily indicate infection in the infant. The diagnosis of HIV infection in an infant less than 18 months of age is made the basis of an assay that looks for the presence of the virus itself (virological tests such as viral culture, DNA polymerase chain reaction (PCR), RNA PCR). Two positive HIV DNA PCR results on separate blood samples serve as the preferred virological method to confirm HIV infection during infancy.

HIV exposed but uninfected newborns serorevert and become ELISA negative by the age of 18 months. HIV infection can be definitively excluded if HIV IgG antibody is negative in the absence of agammaglobulinaemia at age 18 months and if the child has negative virological assays and no clinical symptoms of HIV infection.

We report a HIV infected child who had negative ELISA, western blot, and DNA PCR at the age of 4 years, following durable suppression of HIV viraemia on highly active antiretroviral therapy (HAART).

Abbreviations: ELISA, enzyme linked immunosorbent assay; Ext PC, external low positive control; HAART, highly active antiretroviral therapy; HPC, high positive control; NC, negative control; OD, optical density; PC, positive control; $\mathrm{PCR}$, polymerase chain reaction; VL, viral load; WB, western blot; WPC, weak positive control

\section{CASE HISTORY}

These clinical and laboratory observations were exempted from institutional review board approval at our institution. Parental consent for publication was obtained and retained by the authors in compliance with the institutional review board and HIPAA (Health Insurance Portability and Accountability Act of 1996, USA).

A 4 year old African-American child born in the United States carrying the diagnosis of perinatal HIV-1 infection was referred to our clinic from another centre. Accompanying records indicated that he had received standard peripartum prophylaxis with zidovudine. HIV viral load (VL) had been continuously undetectable $(<400$ copies/ml on HIV RNA PCR) on HAART with zidovudine, lamivudine, and ritonavir since 10 months of age at the referring hospital.

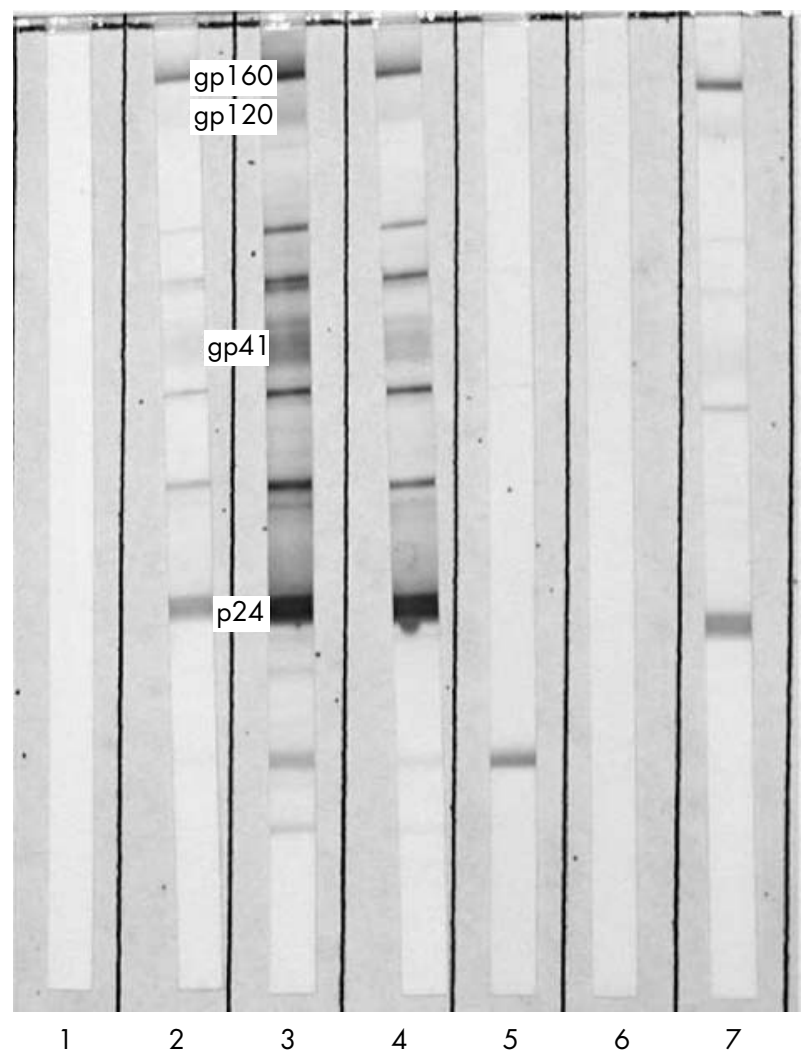

Figure 1 Western blot performed in house while the patient was on HAART. Lane 1 is the negative control showing no bands. Lane 2 is the weak positive control showing low intensities of gpl60/120,41, and 24. Lane 3 is the high positive control showing high intensity of the these bands. Lane 4 is a confirmed positive patient specimen. Lane 5 is an indeterminate specimen. Lane 6 is the specimen from our patient showing no bands. Lane 7 is an external weak positive control. 
When a new patient is referred to our clinic, it is our practice to document the pre-existing HIV diagnosis especially if requested by the parent. In children older than 18 months, we routinely use HIV-1 ELISA for confirmation. This patient's ELISA was unexpectedly reported negative and in house western blot (WB) showed no bands (fig 1). The sample was retested, and the possibility of a mix up in the clinic or laboratory systematically excluded. On the same blood sample, the CD4 count $\left(1209 \times 10^{6} / 1,36 \%\right)$, total immunoglobulin level, IgG, IgM, and IgG subclasses were normal. Repeat testing at our reference laboratory (Wadsworth, Albany NY, USA) labelled this child as HIV negative, based on ELISA, indeterminate WB, and negative HIV DNA PCR (PCR). However, the referring hospital as well as the reference laboratory confirmed that before therapy had been initiated at 10 months of age, the PCR was positive and was associated with a $5 \log _{10}$ copies/ml viral load on quantitative RNA PCR assay (table 1, fig 1).

With the absence of positive confirmatory tests at our centre, the caregiver requested that we verify the diagnosis. To enable diagnosis, HAART was stopped after advising the caregiver of the risk of treatment interruption resulting in possible resistance. Eight weeks later, VL was $>5 \log _{10}$, ELISA, WB, and PCR became positive. HAART was reinstituted with zidovudine, lamivudine, and lopinavir/ritonavir used in combination, and VL fell to $<50$ copies/ml. Currently, the child is clinically asymptomatic, the viral load still undetectable $(<50$ copies $/ \mathrm{ml})$, last CD4 count 1255 cells $\times 10^{6} / 1(37 \%)$, HIV-1 ELISA and WB remain positive after 34 months of therapy.

\section{LABORATORY ASSAYS - METHODS AND DIAGNOSTIC CRITERIA ELISA}

Performed in house using Genetic Systems rLAV EIA (BioRad Laboratories, Redmond, WA, USA) and at the reference laboratory using Vironostika HIV-l Microelisa System (Organon Teknika Corp, Durham, NC, USA). In both laboratories, testing was performed in two separate runs. Each run has two wells of positive control (PC) and three wells of negative control (NC). External low positive control (Ext PC) was also included in every run as per laboratory procedure. The cut-off value is the optical density (OD) below which the sample is considered negative. The specimen OD/cut-off OD ratio known as S/C ratio is $>1$ for positive specimens and $<1$ for negative specimens. Specimens that are negative in the two runs are reported final negative and any positive specimen must be confirmed with WB before reporting. The patient specimen was negative while on therapy $(\mathrm{S} / \mathrm{C}$ ratio $=0.8$ and 0.9 ), and became positive ( $\mathrm{S}$ / $\mathrm{C}=8.3$ and 8.0) once HAART was stopped

\section{Western blot}

Performed in house using Genetic Systems HIV-1 Western Blot (Bio-Rad Laboratories, Redmond, WA, USA) and at the reference laboratory using Cambridge Biotech HIV-1 Western Blot Kit (Calypte Biomedical Corp, Berkeley, CA, USA) Each run in either system must have a high positive control (HPC), weak positive control (WPC), and a negative control (NC). Both laboratories use the CDC interpretive criteria for WB results. ${ }^{2}$ A negative specimen should have no bands. A positive specimen should have at least p24 band and one ENV glycoprotein bands (gpl20/160 or gp4l). A band is considered positive only when its intensity is at least equivalent to the gpl20 band in the WPC. A band that is visible but with intensity less than gp120 in the WPC is not considered positive and scored as $(+/-)$. Any specimen that does not meet the criteria for a positive is considered indeterminate. In our patient, the WB performed in house while on HAART had no bands and was reported negative (fig 1). The WB performed at the reference laboratory was positive only for gp120/160, p24 was " $+/-^{\prime \prime}$ and therefore did not meet the criteria to label it positive and was reported as indeterminate. WB performed in house after the patient was off HAART was clearly positive with distinct gp120/160, gp4l, and p24 bands.

\section{HIV RNA quantitation (by RNA PCR)}

Performed in house using the Roche Amplicor HIV-1 Monitor version 1.0 (Roche Diagnostics, Indianapolis, IN, USA). RNA is extracted from patient plasma and amplification, detection, and quantitation performed using the standard or ultrasensitive procedures. The standard viral load assay detection range is 400-750 000 and the ultrasensitive detection range 50-75 000 copies $/ \mathrm{ml}$. In this patient, the viral load was constantly below the detectable limit for one or both assays while on therapy, and rose once HAART was stopped. After reconstituting therapy, the viral load decreased to and remains at $<50$ copies $/ \mathrm{ml}$.

\section{HIV-1 DNA PCR}

Performed at the reference laboratory using their standard in house developed procedure. Lymphocytes from whole blood

Table 1 Laboratory profile in relation to diagnosis and treatment

\begin{tabular}{|c|c|c|c|c|c|}
\hline & At initial diagnosis & \multicolumn{2}{|c|}{ On HAART } & \multicolumn{2}{|c|}{8 weeks off therapy } \\
\hline Age & 10 months & \multirow{2}{*}{\multicolumn{2}{|c|}{$\begin{array}{l}49 \text { months } \\
\text { Negative }\end{array}$}} & \multicolumn{2}{|c|}{57 months } \\
\hline HIV-1 ELISA & Positive & & & Positi & \\
\hline \multicolumn{6}{|l|}{ Raw optical density } \\
\hline Cut off & Not available & 0.27 & 0.27 & 0.28 & 0.29 \\
\hline Positive control (PC) & Not available & 1.77 & 1.85 & 2.1 & 2.0 \\
\hline Negative control & Not available & 0.02 & 0.02 & 0.03 & 0.04 \\
\hline External low PC & Not available & 0.87 & 0.68 & 0.94 & 0.88 \\
\hline Patient & Not available & 0.26 & 0.23 & 2.34 & 2.38 \\
\hline $\begin{array}{l}\text { Patient/cut off ratio ( }>1=\text { positive, } \\
<1=\text { negative) }\end{array}$ & Not available & 0.94 & 0.83 & 8.3 & 8.0 \\
\hline $\begin{array}{l}\text { Western blot } \\
\text { Visible bands }\end{array}$ & Positive & \multicolumn{2}{|c|}{ Negative } & \multicolumn{2}{|c|}{ Positive } \\
\hline gpl60 & Not available & \multicolumn{2}{|c|}{ Absent } & \multicolumn{2}{|c|}{ Present } \\
\hline gpl20 & Not available & \multicolumn{2}{|c|}{ Absent } & \multicolumn{2}{|c|}{ Present } \\
\hline gp41 & Not available & \multicolumn{2}{|c|}{ Absent } & \multicolumn{2}{|c|}{ Present } \\
\hline p24 & Not available & \multicolumn{2}{|c|}{$\begin{array}{l}\text { "+/" (Band intensity < gpl20 } \\
\text { in the Weak Positive Control) }\end{array}$} & \multicolumn{2}{|c|}{ Present } \\
\hline DNA PCR & Positive & \multicolumn{2}{|c|}{ Negative } & \multicolumn{2}{|c|}{ Positive } \\
\hline RNA PCR (copies/ml) & $>5 \log _{10}$ & \multicolumn{2}{|c|}{$<400$} & \multicolumn{2}{|c|}{$>5 \log _{10}$} \\
\hline CD4 count (cells $\left.\times 10^{6} / \mathrm{l}\right)$ & Not available & \multicolumn{2}{|c|}{$1209(36 \%)$} & \multicolumn{2}{|c|}{$716(26 \%)$} \\
\hline
\end{tabular}


are used to look for any proviral DNA. The DNA is quantitated typically using $1 \mu \mathrm{g}$ of template for the PCR. The end product detection is accomplished by liquid hybridisation to a P32 labelled probe, followed by separation of probe target duplex from unhybridised probe by polyacrylamide gel electrophoresis. In our patient, PCR analysis was performed twice on the sample while the patient was on HAART, the second time using an increased amount of target DNA. No bands were observed in either assay.

\section{DISCUSSION}

The detection of circulating antibodies to HIV-1 by ELISA in children over 18 months of age is essential for HIV infection. A negative ELISA/WB and DNA PCR in an older child with HIV infection that is proved is an unexpected finding.

Our patient had a normal CD4 counts, undetectable VL, negative HIV-1 ELISA, and normal immunoglobulin level at the initial visit to our clinic. Under routine diagnostic guidelines, this patient would have been declared uninfected or even worse, perceived by the parent to be "cured" of HIV. The fact that the HIV DNA PCR was negative further confounded the situation.

The likely explanation for these findings is that in our patient, complete and prolonged viral suppression had led to the absence of circulating viraemia detectable by DNA PCR. The absence of virological stimuli for antibody production despite a functional immune system resulted in a negative ELISA. This situation has been described in HIV infected newborns initiated on early HAART. ${ }^{3}$ Negative ELISA resulted following prolonged viral suppression in these neonates. In older children, although HAART for HIV-1 infection can reduce levels of HIV-1 RNA in plasma to below the limit of detection, replication competent forms of the virus persist in all infected individuals. One form of persistence involves a stable reservoir of latent but potentially infectious virus that resides in resting memory CD4+ T cells. ${ }^{4}$ HIV infected children who respond to HAART have reconstitution of recent thymic emigrant $\mathrm{T}$ cells expressing $\mathrm{T}$ cell receptor excision circles, decreased immune activation, and lower effector CD8+ T cells. Successful HAART allows the increment of activated CD4+ T cells ${ }^{5}$; but these new cells originating from the thymus are naive CD4(+)CD45RA(+) lymphocytes and are less susceptible to HIV-1 infection than are the memory lymphocytes that dominate immune reconstitution in adults. ${ }^{6}$ This is a plausible mechanism for the apparent disappearance of laboratory markers of HIV infection in our patient while on therapy. Resurgence of viraemia from latent reservoirs upon interruption of HAART enabled confirmatory tests to again become positive.

Spontaneous and permanent clearance of HIV infection and its markers has been reported in a single case. ${ }^{7}$ However, this situation differs from our case because interruption of HAART led to rebound of detectable viraemia and positive seroconversion. Although the appearance of HIV-1 antibody after HAART induced immune reconstitution in previously seronegative infants has been reported, ${ }^{89}$ our case describes the first instance of an immune competent older child on effective HAART with negative ELISA and PCR.

Patients with HIV/AIDS frequently question the need for ongoing therapy. Negative serological tests and HIV PCR while on treatment may lead to an erroneous self declaration of cure by the patient. This becomes especially relevant with the availability of rapid, home based HIV antibody testing. ${ }^{10}$

Patients and providers should exercise caution in interpreting negative serological tests in children on HAART.

\section{Key messages}

- Prolonged suppression of detectable viraemia can potentially eliminate serological evidence of HIV infection in children

- Serological tests in patients on HAART should be interpreted carefully by providers and patients

Treatment interruption may be needed to reconfirm the diagnosis of HIV infection when in doubt, as this phenomenon may become more prevalent with aggressive HAART.

\section{ACKNOWLEDGEMENTS}

The authors thank Tim Sullivan, Pediatric HIV PCR Testing Laboratory, Wadsworth Center for Laboratories and Research, New York State Department of Health, Albany, NY, USA, for providing data related to confirmatory tests done at the reference laboratory.

\section{CONTRIBUTORS}

ND followed the child in their clinic and reviewed the medical charts from the referring facility; MM collected the clinical details and laboratory data during patient follow up; details of laboratory tests performed to confirm HIV infection and their results were described by KA; all authors participated in the preparation of the manuscript.

\section{Authors' affiliations}

N Desai, M Mathur, K Abu-Lawi, Department of Pediatrics and Pathology, Kings County Hospital Center and SUNY Downstate Medical Center, Brooklyn, NY, USA

There are no financial disclosures or conflicts of interest applicable.

Correspondence to: Ninad Desai, MD, Kings County Hospital, B 6202, 451 Clarkson Avenue, Brooklyn, NY 11203, USA; desain@nychhc.org

Accepted for publication 14 December 2004

\section{REFERENCES}

1 National Institutes of Health. Guidelines for the use of antiretroviral agents in pediatric HIV infection, 25 June 2003.Available at www.aidsinfo.nih.gov/ guidelines/default_db2.asp?id=51, accessed on 12 February, 2004.

2 Centers for Disease Control (CDC). Interpretive criteria used to report western blot results for HIV-1-antibody testing-United States. Morb Mortal Wkly Rep 1991;40:692-5.

3 Luzuriaga K, McManus M, Catalina M, et al. Early therapy of vertical human immunodeficiency virus type 1 (HIV-1 infection): control of viral replication and absence of HIV-1 specific immune responses. J Virol 2000;74:6984-91.

4 Ruff C, Ray C, Kwon P, et al. Persistence of wild-type virus and lack of temporal structure in the latent reservoir for human immunodeficiency virus type 1 in pediatric patients with extensive antiretroviral exposure. $J$ Virol 2002;76:9481-92.

5 Resino S, Galan I, Bellon JM, et al. Characterizing the immune system after long-term undetectable viral load in HIV-1-infected children. J Clin Immunol 2003;23:279-89.

6 Saitoh A, Powell CA, Fenton T et al. Longitudinal analysis of lymphocyte ratios and HIV-1 intracellular DNA levels in children. J Infect Dis 2004; 189:1216-20

7 Bryson, Y, Pang S, Wei L, Dickover R, et al. Clearance of HIV infection in a perinatally infected infant. N Engl J Med 1995;332:833-8.

8 De Rossi A, Giaquinto C, Del Mistro, A et al. Onset of HIV-1 antibody production after highly active antiretroviral therapy in a seronegative HIV-1infected child. AIDS 2000;14:1284-6.

9 Fraaij P; Van Rossum A; Wolthers K et al. Initiation of highly active antiretroviral therapy leads to an HIV-specific immune response in a seronegative infant. AIDS 2003;17:138-140.

10 FDA News, FDA approves new rapid HIV test kit. 7 Nov 2002, 02-49, available at www.fda.gov/bbs/topics/NEWS/2002/NEW00852.html, accessed 12 February, 2004. 